\title{
No Evidence for Increased Brain Tumour Incidence in the Swedish National Cancer Register Between Years 1980-2012
}

\author{
JONAS NILSSON ${ }^{1,2,3}$, JACOB JÄRÅS ${ }^{4}$, ROGER HENRIKSSON ${ }^{2,4}$, GEORG HOLGERSSON ${ }^{5}$, \\ STEFAN BERGSTRÖM ${ }^{1,6}$, JIMMY ESTENBERG ${ }^{7}$, TORSTEN AUGUSTSSON ${ }^{7}$ and MICHAEL BERGQVIST ${ }^{1,2,6}$ \\ ${ }^{1}$ Center for Research and Development, Uppsala University/County Council of Gävleborg, \\ Gävle Hospital, Gävle, Sweden; \\ ${ }^{2}$ Department of Radiation Sciences and Oncology, Umeå University, Umeå, Sweden; \\ ${ }^{3}$ Department of Radiology, Gävle Hospital, Gävle, Sweden; \\ ${ }^{4}$ Regional Cancer Center Stockholm-Gotland, Stockholm, Sweden; \\ ${ }^{5}$ Department of Immunology, Genetics and Pathology, Uppsala, Sweden; \\ ${ }^{6}$ Department of Oncology, Gävle Hospital, Gävle, Sweden; \\ ${ }^{7}$ Swedish Radiation Safety Authority, Stockholm, Sweden
}

\begin{abstract}
Background/Aim: The main objective of this study was to evaluate if there was an increased incidence of brain tumours between years 1980-2012, a time period when mobile phone usage has increased substantially. Materials and Methods: From the Swedish Cancer Registry, cases of meningiomas, low-grade gliomas (LGG) and high-grade gliomas $(H G G)$ were identified in patients between 1980 2012. Direct age-standardised incidence rates were used to calculate incidence trends over time. Results: A total of 13,441 cases of meningiomas, 12,259 cases of high-grade gliomas and 4,555 cases of $L G G$ were reported to the register during the study period. The results suggest that there may be a negative development in the trend for $L G G$ of -0,016 cases per 100,000 and year, corresponding to a mean reduction of approximately $1 \%$ per year. Conclusion: The present study was not able to demonstrate an increased incidence of glioma during the past 30 years in Sweden.
\end{abstract}

Tumours in the central nervous system (CNST) are divided according to the 2007 WHO classification, using a four-point scale based on histopathological assessment (1). There are more than 100 types of brain tumours. Most are derived from glial cells that support the brain cells; these are called

This article is freely accessible online.

Correspondence to: Michael Bergqvist, Professor in Oncology, Senior Consultant in Oncology, Department of Radiology, Gävle Hospital, SE-801 87 Gävle, Sweden. Tel: +46 26154000, e-mail: michael.bergqvist@regiongavleborg.se

Key Words: Survival, brain tumours, incidence. gliomas. Meningiomas on the other hand, arise from the meninges of the brain, account for approximately one third of all intracranial brain tumours in adults, and have a female predominance. Frequently they are discovered by chance, and surgical resection is used for histopathological diagnosis and tumour removal (2).

In the clinical setting, the grading system is an important tool for deciding the choice of therapy, particularly adjuvant radiation and chemotherapy (3). The grading definition is made by a pathologist based on histology of the tumour. A tumour with a histology close to normal is generally defined as grade I, whilst a tumour with an abnormal histology is classified as a high-grade tumour, WHO grade III or IV. Such high-grade tumours are regarded as malignant and these are generally fast growing, often relapse and may spread to other parts of the brain or the spinal cord. Low-grade tumours (WHO I-II) on the other hand generally grow slowly, are less likely to relapse, normally do not spread and may be treated by surgery alone.

The incidence rate of CNST has been reported by numerous studies. These have been based on register data most frequently supplied by the Central Brain Tumor Registry of the United States, but there are also studies based on European registry data (4-6). Various findings have been presented, and, to our knowledge, no major consistent trend for change in incidence of CNST has been observed in recent years. By using registry data, we aimed to investigate the trend in ageadjusted incidence of meningiomas, and high- (HGG) and low-grade (LGG) gliomas in Sweden. Since the use of mobile phones have increased during the past two decades, our primary goal was to study if there was an increase in incidence rate during the years 1980 to 2012 . We also stratified the analysis to four different age groups in order to see if the incidence rate had increased in any specific group. 


\section{Materials and Methods}

Brain tumour cases were identified between 1980-2013 from the Swedish Cancer Registry. However, in the analysis of the development of the incidence trend, only cases diagnosed between the years 1980 to 2012 were included. The reason for this was the delay in the registration of the tumours in the Swedish Cancer Registry in later years that led to a misrepresentation of the actual number of tumours, specifically in 2013.

Classification of the tumours in the Swedish Cancer Registry during the period of study follow the International Classification of Diseases (ICD)-7 (7). The tumours were included in the study if their ICD-7 codes were 193 and if their pathological codes were either 461, 463 or 466 (meningioma), 475 (LGG) or 476 (HGG). In cases where the patients had been diagnosed with more than one brain tumour, only the first tumour per diagnosis and patient was included.

In this report, direct age-standardised incidence rates were calculated to measure trends over time. Direct age-standardisation requires that the age-specific rates of the study population is known. Age-specific incidence rates were then calculated using 5-year age bands, producing a total of 18 groups $(0-4 ; 5-9 ; 10-14 ; 15-19 ; 20-24$; $25-29 ; 30-34 ; 35-39 ; 40-44 ; 45-49 ; 50-54 ; 55-59 ; 60-64 ; 65-69 ; 70-$ $74 ; 75-79 ; 80-84 ; \geq 85$ years) and then applied to the distribution of the general Swedish population year 2000. The age-specific incidence rates were then summed to give the age-standardised rate. Age-standardisation is important when comparing rates between different groups or over time since age has a strong influence on the risk of developing cancer.

In order to assess possible differences in the trend of the diagnosis during the study period, linear regression was used to fit a model to the age-standardised incidence rates with year of diagnosis as covariate.

The study was reviewed and approved by a central Ethic Review Board (Uppsala, Sweden, reference no. 2015/313).

\section{Results}

Between 1980 to 2012, a total of 13,441 (44.4\%) new cases of meningiomas, $12,259(40.5 \%)$ new cases of HGG and $4,555(15.1 \%)$ new cases of LGG were reported to the register (Table I, Figure 1).

The results from the analysis suggest that there may be a negative development in the trend for LGG of -0.016 cases per 100,000, with a mean decrease per year of approximately $1 \%$ (Table II, Figure 2). In all age groups except those aged 0-39 years, significantly negative trends in incidence were seen (Table II).

Moreover, a negative development in the trend for meningiomas of -0.037 (95\% CI $=-0.050-0.024, p<0.001)$ cases per 100,000 , and a positive estimated trend of 0.036 (95\% CI $=0.016$ to $0.056, p=0.001$ ) cases per 100,000 was seen in men and women, respectively. In the age groups 0 39 years, 40-59 years and 60-74 years, there was a positive trend for meningiomas during the study period. However, in patients older than 75 years, results show a significant negative trend (Table III).
Table I. Number of cases per diagnosis.

\begin{tabular}{lcc}
\hline Diagnosis & Cases, $\mathrm{n}$ & Proportion, $\%$ \\
\hline Meningioma & 13,441 & 44.4 \\
Low-grade glioma & 4,555 & 15.1 \\
High-grade glioma & 12,259 & 40.5 \\
Total & 30,255 & 100 \\
\hline
\end{tabular}

Table II. Regression statistics.

\begin{tabular}{|c|c|c|c|c|}
\hline Diagnosis & $\begin{array}{c}\text { Cases, } \\
\mathrm{n}\end{array}$ & $\begin{array}{l}\text { Incidence trend } \\
\text { estimate }\end{array}$ & $95 \% \mathrm{CI}$ & $p$-Value \\
\hline Meningioma & 13,441 & 0.001 & $-0.013-0.014$ & 0.914 \\
\hline Low-grade glioma & 4,555 & -0.016 & $-0.024-0.007$ & 0.001 \\
\hline High-grade glioma & 12,259 & -0.002 & $-0.011-0.008$ & 0.708 \\
\hline
\end{tabular}

CI: Confidence interval.

For HGG, there was a trend for slightly decreased incidence in the age group 0-39 years (incidence trend estimate $=-0.004,95 \% \mathrm{CI}=-0.006-0.001 ; p=0.005)$ and a trend for mildly increased incidence in the age group 60-74 years (incidence trend estimate $=0.006,95 \% \mathrm{CI}=0.001-0.012$; $p=0.029)$.

A total of 113 of the patients in the study had been diagnosed with two tumours of different types $(0.2 \%, n=33$ of patients with meningiomas; $1.1 \%, \mathrm{n}=49$ of patients with LGG; and $0.3 \%, \mathrm{n}=31$ of patients with $\mathrm{HGG}$ as primary tumours respectively).

\section{Discussion}

The present article is based on all new registered patients with brain cancer in the National Brain Tumour Registry in Sweden from 1980 up to and including 2012. This included a total of 13,441 new cases of meningioma, 12,259 new cases of HGG and 4,555 new cases of LGG. Our data demonstrate a negative development in the trend for LGG of -0.016 cases per 100,000 , corresponding to a mean decline per year of approximately $1 \%(p=0.001)$. These data are of interest since the technology used to find primary brain tumours during the 1980s was inferior in comparison with the available technology during later years (introduction of magnetic resonance imaging and positron-emission tomography) and thus, the decrease of LGG might be even higher, however this is only speculative.

As seen in Figure 2, there was a temporal increase in the annual incidence rate from the mid-1980s to the mid-1990s, plausibly driving the decreasing trend of incidence in LGG 


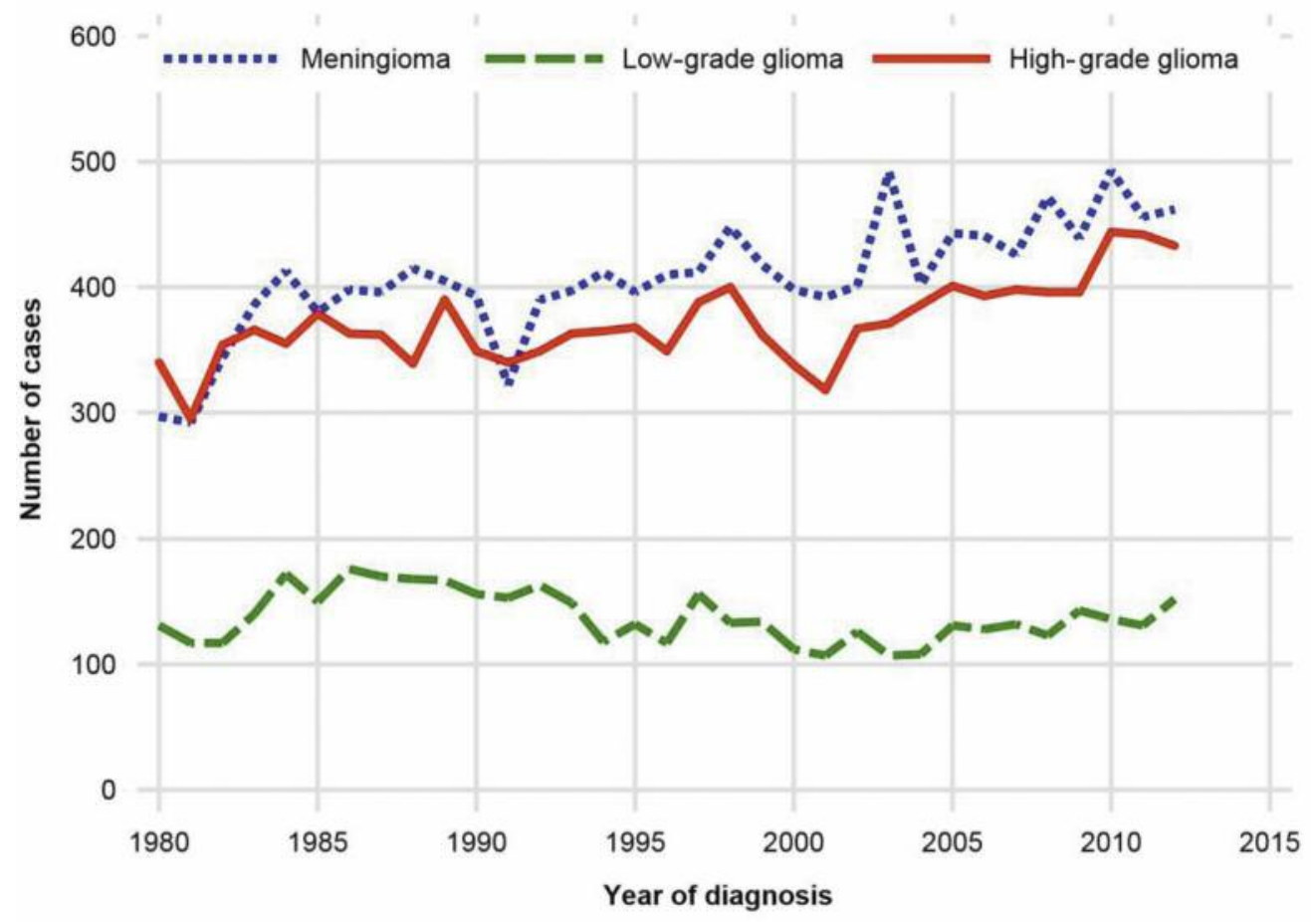

Figure 1. Total number of cases by tumour site, 1980-2012.

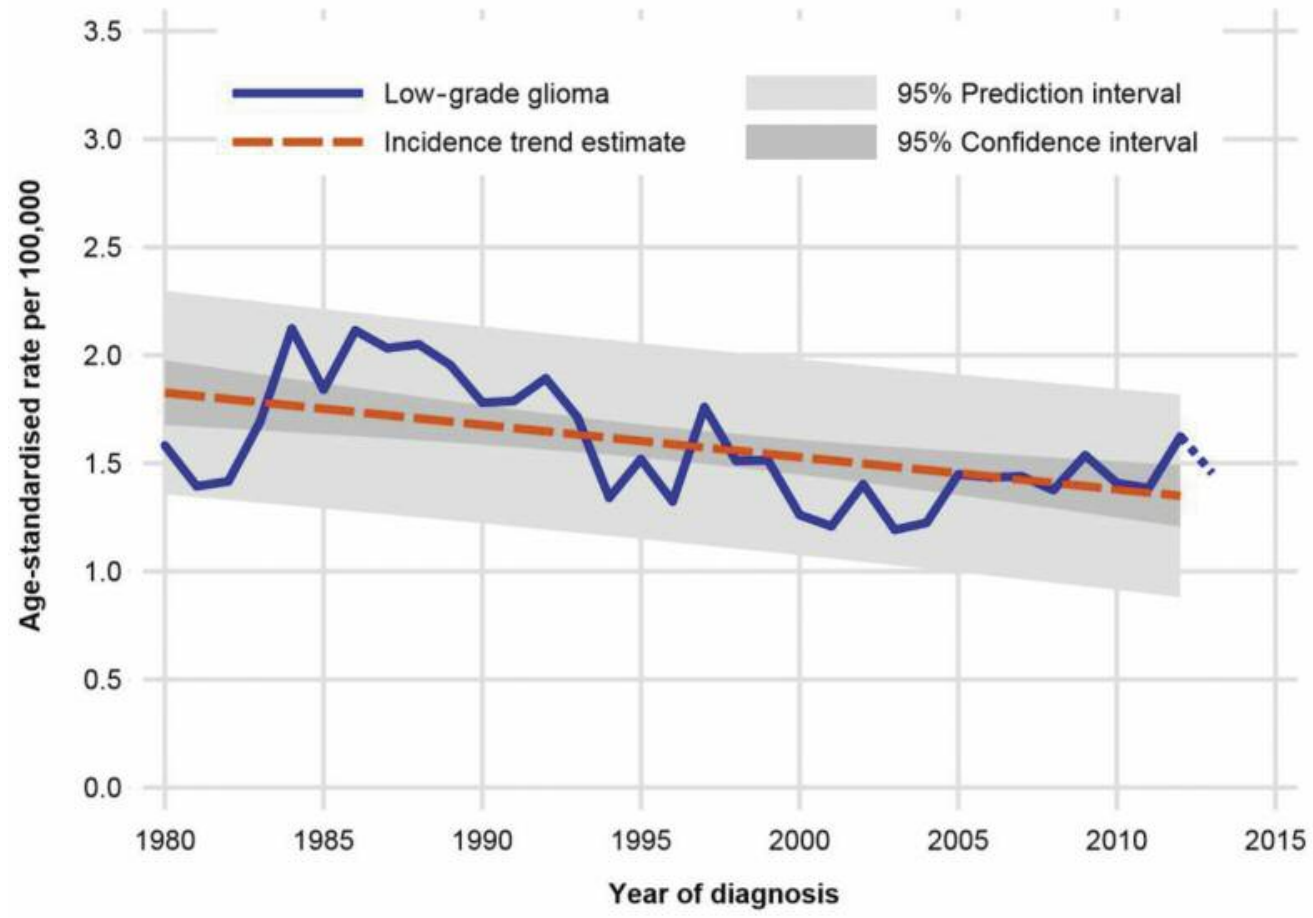

Figure 2. Incidence trend estimate and 95\%CI \& PI of the annual incidence for low-grade gliomas, 1980-2012. 
Table III. Incidence trends by diagnosis, gender and age.

\begin{tabular}{|c|c|c|c|c|c|c|}
\hline Diagnosis & & Group & Cases, $\mathrm{n}$ & Incidence trend estimate & $95 \% \mathrm{CI}$ & $p$-Value \\
\hline \multirow[t]{7}{*}{ Meningioma } & & All & 13,441 & 0.001 & $-0.013-0.014$ & 0.914 \\
\hline & \multirow[t]{2}{*}{ Gender } & Men & 4,021 & -0.037 & $-0.051--0.023$ & $<0.001$ \\
\hline & & Women & 9,420 & 0.042 & $0.023-0.062$ & $<0.001$ \\
\hline & \multirow[t]{4}{*}{ Age } & $0-39$ years & 947 & 0.007 & 0.004-0.009 & $<0.001$ \\
\hline & & $40-59$ years & 4,462 & 0.003 & $0.023-0.036$ & $<0.001$ \\
\hline & & $60-74$ years & 4,925 & 0.009 & $0.003-0.015$ & 0.015 \\
\hline & & $\geq 75$ years & 3,107 & -0.045 & $-0.054--0.036$ & $<0.001$ \\
\hline \multirow[t]{7}{*}{ Low-grade glioma } & & All & 4,555 & -0.016 & $-0.024--0.007$ & 0.001 \\
\hline & \multirow[t]{2}{*}{ Gender } & Men & 2,502 & -0.020 & $-0.003-0.009$ & $<0.001$ \\
\hline & & Women & 2,053 & -0.012 & $-0.022--0.002$ & 0.017 \\
\hline & \multirow[t]{4}{*}{ Age } & $0-39$ years & 2,361 & -0.001 & $-0.006-0.003$ & 0.566 \\
\hline & & $40-59$ years & 1,295 & -0.005 & $-0.009--0.001$ & 0.021 \\
\hline & & $60-74$ years & 706 & -0.005 & $-0.008--0.003$ & $<0.001$ \\
\hline & & $\geq 75$ years & 193 & -0.004 & $-0.005--0.003$ & $<0.001$ \\
\hline \multirow[t]{7}{*}{ High-grade glioma } & & All & 12,259 & -0.002 & $-0.011-0.008$ & 0.708 \\
\hline & \multirow[t]{2}{*}{ Gender } & Men & 7,124 & 0.002 & $-0.016-0.019$ & 0.822 \\
\hline & & Women & 5,135 & -0.008 & $-0.017-0.002$ & 0.097 \\
\hline & \multirow[t]{4}{*}{ Age } & $0-39$ years & 1,340 & -0.004 & $-0.006-0.001$ & 0.005 \\
\hline & & $40-59$ years & 4,321 & -0.001 & $-0.006-0.004$ & 0.640 \\
\hline & & $60-74$ years & 5,439 & 0.006 & 0.001-0.012 & 0.029 \\
\hline & & $\geq 75$ years & 1,159 & -0.003 & $-0.009-0.002$ & 0.223 \\
\hline
\end{tabular}

CI: Confidence interval.

and the results should therefore be interpreted with caution. However, since the mid-1990s, the annual incidence rate seems unchanged. The reason for this temporal increase is hard to explain, but a natural cyclicity of incidence might partly explain the curve $(8,9)$. Another possible explanation is improved diagnostic technology, which may have slightly shortened the time to discovery and thus given a seemingly increased incidence rate for a short period of time.

A discrete positive trend in incidence of meningiomas was seen for all ages except the highest age group ( $\geq 75$ years), where a negative trend was seen. A possible explanation for this might be a higher chance of early incidental discovery due to increased availability of advanced diagnostic technology following head trauma and stroke symptoms (10). For LGG, all age groups but 0-39 years showed a negative trend. This might also be explained by an improved diagnostic availability and earlier discovery in the age group that holds the majority of cases (0-39 years), thus leaving fewer to be discovered in later years.

Our overall results show a relatively stationary agestandardised incidence rate of brain tumours during a study period when mobile phone usage has increased substantially. However, as many other lifestyle and environmental factors have changed during the past three decades, correlation cannot be ruled out completely.

The use of data available from registries has pros and cons. The advantage is that a large number of individuals can be identified, resulting in a sufficient number of patients that can make the statistical calculations more robust and trustworthy. The cons are that the registration of the individual patient's data is not always $100 \%$ correct and the results from statistical analyses must therefore always be interpreted with caution.

However, our data consist of a large number of individualspecific observations and data from the Swedish National Cancer Registry have been evaluated in several large studies, indicating that the quality of available data is fair and robust. For example, a completeness test of the register was made by Barlow et al. in 2009, who estimated under-reporting of about $4 \%$ based on data from 1998 and all available cancer entities. Thus the quality and completeness of the Swedish cancer registry is considered to be high and comparable to other high quality registries in Northern Europe (11). Data from our study are concordant with data from Asklund et al. (12), which used data from both the Swedish National Cancer Registry as well as from the Swedish Brain Tumour Registry between years 1999-2012. They showed a clear increase of the incidence rate for all primary CNSTs in total. However, during the same time period, the age-adjusted incidence rate was essentially constant. Thus, the increasing age of the population seems to play a major role in the absolute increase of incidence. Asklund et al. also showed that incidence rates of primary CNSTs in both men and women was relatively constant in Sweden, whilst the incidence rates in both sexes had slightly increased in Norway, Denmark and Finland (12). 
Our results are consistent with a nationwide Israeli study based on cancer registry data, performed by Barchana et al. in 2012, who showed a significant decrease in LGG (WHO grade II) between years 1980-2009 (13). Similarly, Little et al. showed significantly decreasing incidence trends of LGG from 1992 through 2008 based on United States registry data (14). However, other studies have shown increasing trends of incidence. For example, Legler et al. showed increasing incidence rates of gliomas, especially in elderly patients, between 1975-1995 (15) and Lönn et al. found a slight annual increase of the incidence rate in gliomas from 1968 through 1998 among the Scandinavian population. The main increase was however seen between 1977 and 1983, and incidence has since then been relatively stable (6). Thus, several of these studies discuss that the increasing trend may be an artifact of improvement in diagnostic technology and practice $(15,16)$.

For meningiomas, various results have been previously reported, most showing increasing trends of incidence. For example, Deltour et al. analysed the annual percentage change of age-standardized incidence rate among the Scandinavian population between 1974 and 2003 and showed an annual incidence rate increase of $0.8 \%$ in men and $2.9 \%$ in women (17). Hoffman et al. also showed increased incidence rates of meningiomas between 1985 and 1999. However, no age-, gender-, or race-specific trends were significant (18). Gittleman et al. showed a significant increase in the annual percentage change of age-standardized incidence rates of non-malignant meningiomas in United States population between 20042010, however, the authors also showed a significant decrease of malignant meningiomas between 2000 and 2007 (4). Thus, seemingly the trend of incidence rates in meningiomas, not otherwise specified, might be lowered by the decreasing trend in incidence of malignant subtypes and consequently that of benign subtypes might possibly be higher than previously reported. Since an increasing number of incidental meningiomas are discovered during imaging of the brain due to conditions such as head trauma or sinus problems, and increased access to improved imaging modalities might be a confounding factor, the observed incidence of meningiomas should be interpreted with caution $(10,17)$.

In conclusion, in the present report that includes a total of 30,255 brain tumours categorised as meningiomas, LGG and HGG, we were not able to show an increased incidence, instead stationary incidence rates of gliomas were recorded during the past three decades.

\section{Funding}

The present study was financially supported by the Swedish Radiation Safety Authority and the Stiftelsen Gävle Cancerfond.

\section{Conflicts of Interest}

The project was ordered and directly financed by the Swedish Radiation Safety Authority to study any association between mobile phone usage and brain tumour development. However, the authors independently performed data collection, analysis and interpretation without any restrictions.

\section{Acknowledgements}

The present study was financially supported by the Swedish Radiation Safety Authority and the Stiftelsen Gävle Cancerfond

\section{References}

1 Louis DN, Ohgaki H, Wiestler OD, Cavenee WK, Burger PC, Jouvet A, Scheithauer BW and Kleihues P: The 2007 WHO Classification of Tumours of the Central Nervous System. Acta Neuropathol 114(2): 97-109, 2007.

2 Fathi AR and Roelcke U: Meningioma. Curr Neurol Neurosci Rep 13(4): 337, 2013.

3 Porter KR, McCarthy BJ, Berbaum ML and Davis FG: Conditional survival of all primary brain tumor patients by age, behavior, and histology. Neuroepidemiology 36(4): 230-239, 2011.

4 Gittleman HR, Ostrom QT, Rouse CD, Dowling JA, de Blank PM, Kruchko CA, Elder JB, Rosenfeld SS, Selman WR, Sloan AE and Barnholtz-Sloan JS: Trends in central nervous system tumor incidence relative to other common cancers in adults, adolescents, and children in the United States, 2000 to 2010. Cancer 121(1): 102-112, 2015.

5 Ostrom QT, Gittleman H, Farah P, Ondracek A, Chen Y, Wolinsky Y, Stroup NE, Kruchko C and Barnholtz-Sloan JS: Cbtrus statistical report: Primary brain and central nervous system tumors diagnosed in the United States in 2006-2010. Neuro Oncol 15(Suppl 2): ii1-56, 2013.

6 Lonn S, Klaeboe L, Hall P, Mathiesen T, Auvinen A, Christensen HC, Johansen C, Salminen T, Tynes $\mathrm{T}$ and Feychting M: Incidence trends of adult primary intracerebral tumors in four Nordic countries. Int J Cancer 108(3): 450-455, 2004.

7 International Classification of Disease, available at: http://www.socialstyrelsen.se/klassificeringochkoder/Documents/ KS64.pdf

8 Dimitrov BD, Shangova-Grigoriadi $\mathrm{S}$ and Grigoriadis ED: Cyclicity in variations of incidence rates for breast cancer in different countries. Folia Med 40(3B Suppl 3): 66-71, 1998.

9 Dimitrov BD: Cyclic patterns of incidence variations for stomach cancer in the north-western region of England. Croat Med J 41(2): 197-202, 2000.

10 Wiemels J, Wrensch $M$ and Claus EB: Epidemiology and etiology of meningioma. J Neurooncol 99(3): 307-314, 2010.

11 Barlow L, Westergren K, Holmberg L and Talback M: The completeness of the Swedish Cancer Register: A sample survey for year 1998. Acta Oncol 48(1): 27-33, 2009.

12 Asklund T, Malmstrom A, Bergqvist M, Bjor O and Henriksson R: Brain tumors in Sweden: Data from a population-based registry 1999-2012. Acta Oncol 54(3): 377-384, 2015.

13 Barchana M, Margaliot M and Liphshitz I: Changes in brain glioma incidence and laterality correlates with use of mobile 
phones - a nationwide population based study in israel. Asian Pac J Cancer Prev 13(11): 5857-5863, 2012.

14 Little MP, Rajaraman P, Curtis RE, Devesa SS, Inskip PD, Check DP and Linet MS: Mobile phone use and glioma risk: Comparison of epidemiological study results with incidence trends in the United States. BMJ 344: e1147, 2012.

15 Legler JM, Ries LA, Smith MA, Warren JL, Heineman EF, Kaplan RS and Linet MS: Cancer surveillance series [corrected]: Brain and other central nervous system cancers: Recent trends in incidence and mortality. J Natl Cancer Inst 91(16): 13821390, 1999.

16 Radhakrishnan K, Mokri B, Parisi JE, O'Fallon WM, Sunku J and Kurland LT: The trends in incidence of primary brain tumors in the population of Rochester, Minnesota. Ann Neurol 37(1): 67-73, 1995.
17 Deltour I, Johansen C, Auvinen A, Feychting M, Klaeboe L and Schuz J: Time trends in brain tumor incidence rates in Denmark, Finland, Norway, and Sweden, 1974-2003. J Natl Cancer Inst 101(24): 1721-1724, 2009.

18 Hoffman S, Propp JM and McCarthy BJ: Temporal trends in incidence of primary brain tumors in the United States, 19851999. Neuro Oncol 8(1): 27-37, 2006.

Received December 6, 2018

Revised December 14, 2018

Accepted December 18, 2018 